\title{
The innovative design of air caps for improving the thermal efficiency of CFB boilers.
}

\author{
LIU, X., ZHU, G., ASIM, T., ZHANG, Y. and MISHRA, R.
}




\title{
The Innovative Design of Air Caps for Improving the Thermal Efficiency of CFB
}

\section{Boilers}

\author{
${ }^{1}$ Xiaozhou Liu, ${ }^{2}$ Guangyu Zhu, ${ }^{3 *}$ Taimoor Asim, ${ }^{4}$ Yu Zhang and ${ }^{5}$ Rakesh Mishra \\ ${ }^{1,2,4}$ School of Material \& Energy, Guangdong University of Technology, Guangzhou 510006, China
}

${ }^{3}$ School of Engineering, Robert Gordon University, UK (AB10 7GJ)

${ }^{5}$ School of Computing \& Engineering, University of Huddersfield, UK (HD1 3DH)

1'Liuzhang852@163.com, ${ }^{2}$ jzwest100@vip.qq.com, ${ }^{3 *}$ t.asim@hud.ac.uk, ${ }^{4}$ lilyzhangyu@163.com, 5r.mishra@hud.ac.uk

\begin{tabular}{|c|c|c|c|}
\hline \multicolumn{4}{|c|}{ Nomenclature } \\
\hline $\mathrm{C}_{\mathrm{i}}$ & Partial derivative & $\bar{\rho}$ & $\begin{array}{l}\text { Average density of the surrounding } \\
\text { medium }\end{array}$ \\
\hline $\mathrm{g}$ & Gravitational acceleration & $\eta_{\mathrm{gl}}$ & Boiler thermal efficiency \\
\hline $\mathrm{h}$ & Air jet penetration length & $\varepsilon$ & Flow velocity inhomogeneity \\
\hline$\xi$ & Nozzle drag coefficient & $\Delta \mathrm{P}$ & Pressure drop \\
\hline$\theta$ or $\phi$ & Jet angle & $\operatorname{Re}$ & Reynolds number \\
\hline $\begin{array}{l}\rho \text { or } \\
\rho_{\mathrm{o}}\end{array}$ & Air density & $\mathrm{R}$ & Jet penetration radius \\
\hline $\mathrm{r}$ & Jet nozzle radius & $\mathrm{u}_{0}$ & Flow velocity in air cap \\
\hline$\eta$ & Dynamic viscosity & $\mathrm{u}_{\mathrm{i}}$ & Local flow velocity in $\mathrm{z}$ direction \\
\hline$l$ & Characteristic length & $\overline{\mathrm{u}}$ & $\begin{array}{l}\text { Average flow velocity in } \mathrm{z} \\
\text { direction }\end{array}$ \\
\hline$l_{1}$ & Orifice diameter of cap outlet & $\mathrm{v} 1$ & Velocity in cross section $l_{1}$ \\
\hline
\end{tabular}




\begin{tabular}{|c|c|c|c|}
\hline$l_{2}$ & $\begin{array}{l}\text { Average value of core pipe diameter } \\
\text { and cap diameter }\end{array}$ & V2 & Velocity in cross section $l_{2}$ \\
\hline$l_{3}$ & Core pipe orifice diameter & V3 & Velocity in cross section $l_{3}$ \\
\hline$l_{4}$ & $\begin{array}{l}\text { Height from top wall of core pipe to } \\
\text { top wall of caps }\end{array}$ & $\mathrm{V} 4$ & Velocity in cross section $l_{4}$ \\
\hline$l_{5}$ & Core pipe diameter & V5 & Velocity in cross section $l_{5}$ \\
\hline
\end{tabular}

\section{Abstract}

Air caps are an effective way of ensuring uniformity of air flow in Circulating Fluidized Bed (CFB) boilers. Published literature on the design and configuration of these air caps is severely limited. In this study, extensive theoretical as well as experimental investigations have been carried out to design novel air caps in order to improve efficiency of CFB boilers. A small-scale test bench of 220t/hr CFB boiler has been developed, integrated with novel air caps. It has been observed that inhomogeneity in air flow velocity decreases from $65.79 \%$ to $21.25 \%$, while the pressure drop decreases by $20 \%$. A mathematic model of air caps has been derived and its accuracy verified through cold tests. Two empirical correlations for calculating the pressure drop and the air jet penetration length of the novel air caps have been obtained and verified. Finally, in order to validate the innovative design of air caps, this methodology has been implemented to a full-scale 220t/hr CFB boiler. The hot test results depict that the thermal efficiency of the boiler has increased from $86.4 \%$ to $91.8 \%$ when tested with the novel air caps in-place, which is equivalent to a saving of 6,000 tons of coal per year.

Keywords: Circulating Fluidized Bed (CFB); Flow uniformity; Mathematic model; Velocity Distribution; Hot test; Error analysis. 


\section{Introduction}

Circulating Fluidized Bed (CFB) boilers, owing to their extensive fuel adaptability and low-cost pollution control, are widely used in power generation [1]. The CFB boilers can easily handle combustion of inferior coal (calorific value of less than 4,000kcal). However, in recent years, numerous reports have pointed out that the thermal efficiency of CFB boilers is lower than expected. For example, $\mathrm{Li}$ [2] has reported that the exhaust flue gas temperature of a 220t/h CFB boiler can be as high as $171.2^{\circ} \mathrm{C}$, with a thermal efficiency of $86.4 \%$, which is lower than the expected design efficiency of $88 \%-90 \%$. This means that almost 5,000 tons of inferior coal is wasted every year. There are almost ten thousand CFB boilers currently in use in China alone. Hence, there is a strong demand to improve the thermal efficiency and minimize the environmental impacts of the CFB boilers.

A CFB boiler utilizes a fluidized bed combustor in which crushed coal particles, smaller than $10 \mathrm{~mm}$ in diameter, are suspended in a stream of upward flowing air. About $60 \%$ of the combustion air, known as primary air, is introduced into the combustion chamber through a set of caps installed on bottom of a CFB boiler's combustion chamber. Air caps are a significant component of a CFB boiler. Appropriate design of air caps is very important for reduction in energy consumption and enhanced operation safety of a CFB boiler [3, 4]. Poor air cap design and non-uniform air flow distribution lead to degradation in its thermal performance. For example, in order to maintain stable and complete combustion, a large amount of air has to be injected into a CFB boiler. The oxygen content in the exhaust flue gas is as high as $12.02 \%$ [2]. A number of small carbon particles remain unburned and are carried out of combustion chamber by the flue gas, raising temperature of the exhaust flue gas significantly. Therefore, the thermal efficiency of the CFB boiler decreases. An effective measure to solve this problem is to use novel air caps. The purpose is to uniformly distribute the primary air into 
the fluidized bed at low-pressure drop, and hence, enhancing the combustion efficiency considerably and reducing air cap erosion. In order to effectively design novel air caps for energy-saving purposes, extensive theoretical and experimental investigations need to be carried out.

Today, there are mainly three kinds of air caps used in fluidized bed boilers, i.e., Arrow-type, Bell-type and T-type air caps. Mirek and Klajny [5] have studied the design method of a two-outlet orifices air nozzle (Arrow-type air cap) with low-pressure drop. It has been found that the air cap design should meet two basic criteria, i.e., the required pressure drop value and the optimal air jet penetration length, which are most important for nozzle design. Furthermore, the values of pressure drop and penetration length can be obtained by cold tests. Niu [6] have investigated the resistance characteristics of Bell-type air caps with ten-outlet orifices in a CFB boiler. The influence of the thickness of the cap, the area of the annular gap and the diameter of the exit hole on the resistance of the air cap is studied through cold test. It has been shown that Bell-type air cap offers more resistance causing considerable erosion. Similar research studies have been carried out on the resistance characteristics of the Bell-type air cap in CFB boilers [7-9] with similar conclusions. Yang et al [10] carried out investigations on the pressure drop characteristic of a float air cap. It has been found out that float nozzle has a higher resistance than Bell-type air cap, which results in the formation of an effective barrier against backflow at low boiler loads. Li and Guo [11] have obtained the resistance characteristic curve of T-type air cap through cold test. It has been shown that this kind of cap has a flow dead zone, which is easy to cause uneven distribution of primary air. Feng et al [12] have studied the resistance characteristics of three typical air caps (Arrow-type, Bell-type and T-type air caps). It has been found that Bell-type cap has the highest resistance but the most uniform primary air distribution in the cross-section of the combustion chamber, among the three types of air caps. Because 
the uniformity of the primary air distribution can induce uniform and stable fluidization across the entire cross-section of the combustion chamber, which is necessary for safe operation of the CFB boilers [13], the Bell-type air caps are most widely used in CFB boilers [14].

However, Bell-type caps encounter many problems in practical applications. For example, a large area of overall dislocation, cover wear, holes plugging and inner core tube rupture and so on [15]. There is an urgent need to improve the design of the Bell-type caps. Unfortunately, very few studies exist on the design improvement of such air caps. Moreover, the available literatures mostly acquire the values of pressure drop and air jet penetration length of the air caps through cold test, and not empirically. However, in practical engineering applications, it is more appropriate to use empirical relationship to design air caps. Therefore, there is a need for empirical design improvements of Belltype air caps. In this study, based on the design of conventional Bell-type air caps, a novel air cap design has been developed. At the same time, empirical correlations to calculate pressure drop and air jet penetration length have been obtained. Moreover, the innovative design of the air cap has been validated by hot test of a full-scale $220 \mathrm{t} / \mathrm{hr}$ CFB boiler. These are the main contents of this study.

\section{Development of Novel Air Cap}

The different stages of development of the novel air caps are discussed in details below.

\subsection{Design issues with conventional Bell-type air caps}

The design of a conventional Bell-type air cap is shown in Fig. 1, including the core tube and the outer cover. 

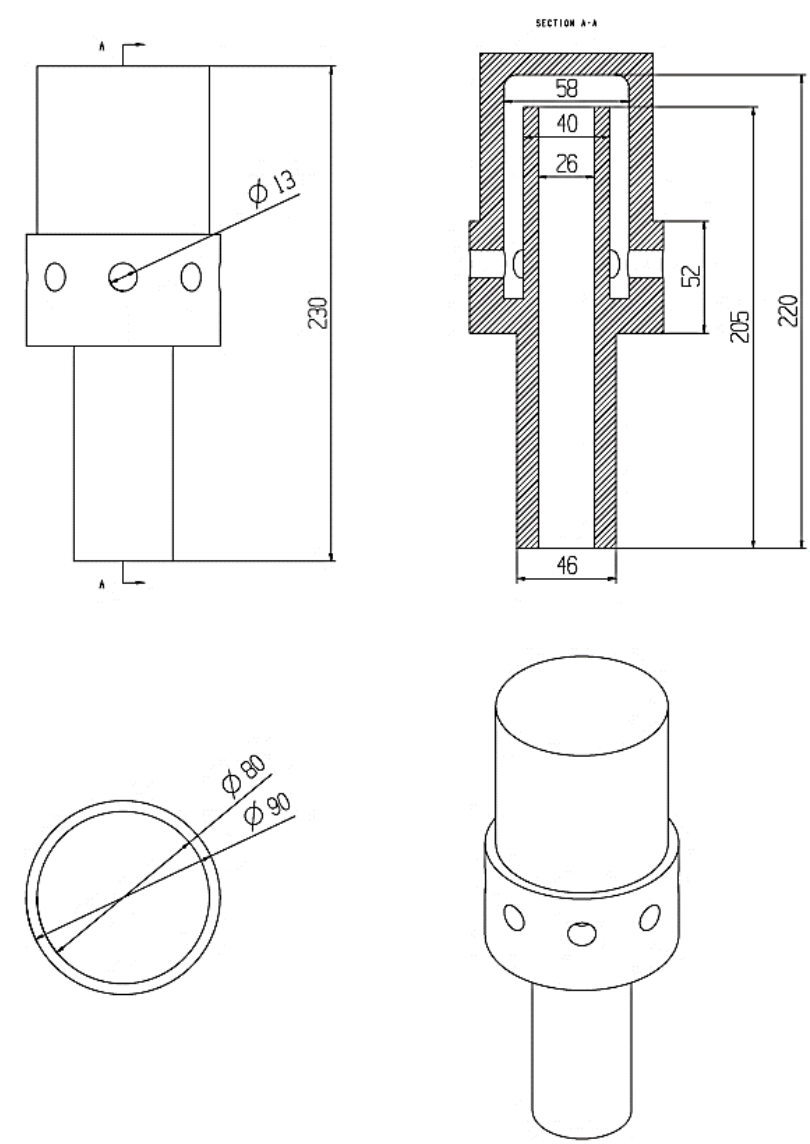

Fig. 1 Conventional Bell-type air cap

There are normally ten small holes on the outer cover of the cap. The primary air jets from these small holes, at very high velocity, into the combustion chamber. This leads to high pressure drop and power consumption. Cover abrasion, cover damage, holes plugging and inner core tube rupture (see Fig. 2 [15]) often occur in Bell-type air caps with large diameter. This causes poor resistance partitions and fluidization of air distribution plate, slag leakage, coking and other accidents, seriously affecting the normal operation of the boiler. 


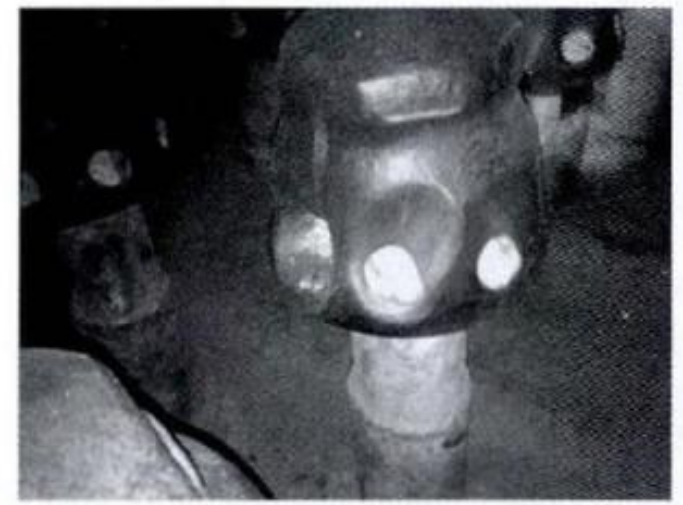

(a) Abrasion

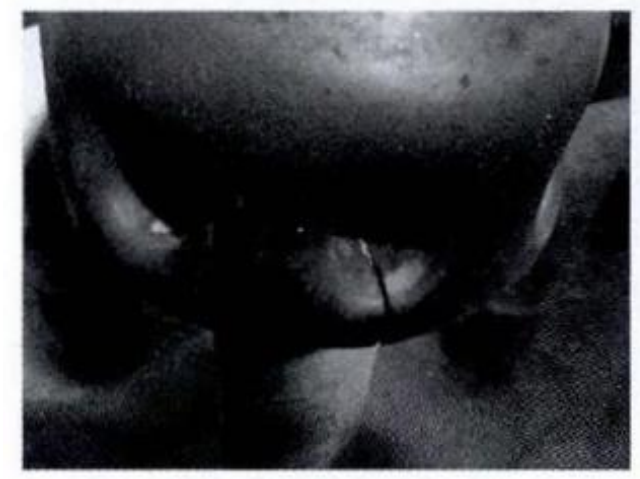

(c) Cover damage

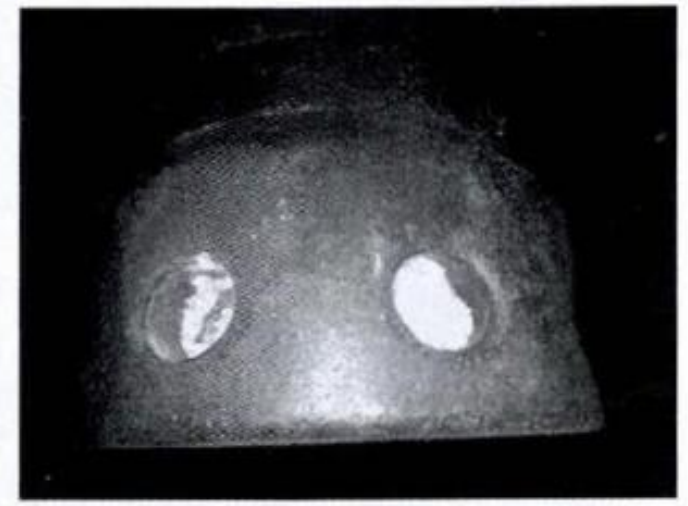

(b) Small holes blockage

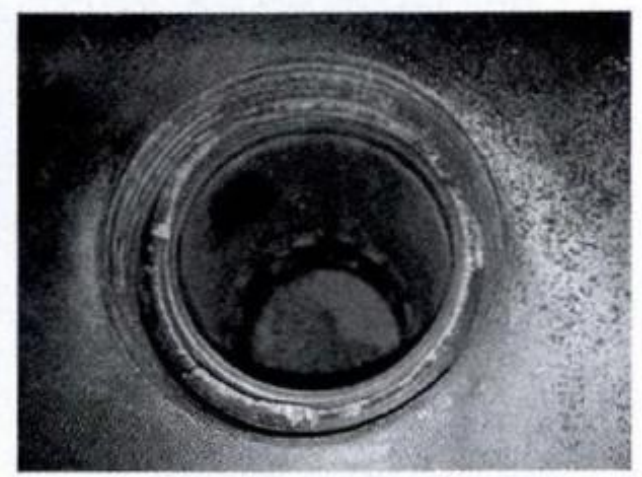

(d) Inner core tube rupture

Fig. 2 Problems of Bell-type air cap in application [15]

Site inspection results show that the improper installation and maintenance is the main cause of these problems [16-17]. When installing Bell-type air cap, the small holes of the cap are required to be arranged against each other, to reduce the ash deposition and prevent air flow from directly impacting the wall surface of the adjacent nozzle [18].

The contact part of core pipe of the cap and the outer cover is provided with a mounting thread, through which the height of the nozzle can be adjusted and the hood can be replaced. Due to the operational environment of the caps, it is easy to jam and deform between the threads. Therefore, in actual use, it does not guarantee the full offset arrangement of Bell-type caps, which results in erosion and wear of a large number of holes in the nozzle. Moreover, during the maintenance and replacement, 
due to the limitations of the site construction conditions, there is a difference in the installation height between the replaced new air cap and the original old air cap, which cannot be adjusted to the same plane (as shown in Fig. 3 [15]). Furthermore, the height of the core pipe is fixed, which results in a large gap between the core pipe and the outer cover of the air cap. These gaps change the resistance characteristics of the Bell-type cap, resulting in a significant pressure drop through the nozzle (the maximum pressure drop can be more than $40 \%$ ).

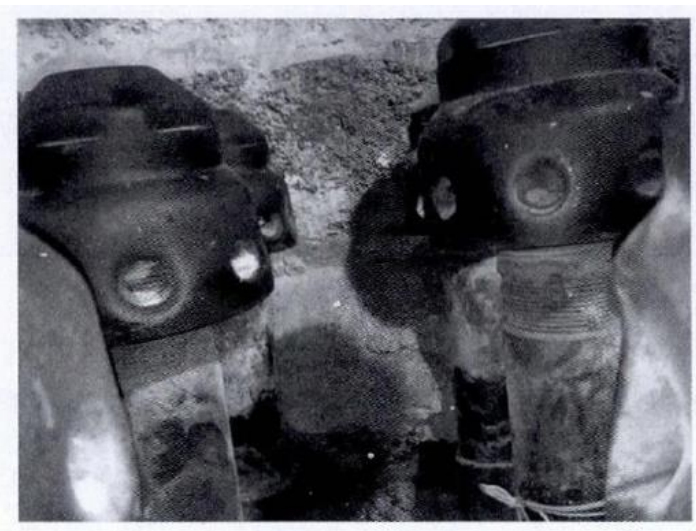

Fig. 3 Install dislocation of air cap [15]

Under the comprehensive effect of the two factors mentioned above, causes the resistance zone of the air distribution plate (the air caps are installed on it) i.e. the resistance in some areas is small, the air volume is large, and the wear of the air cap is aggravating, while the air volume in some areas is small, resulting in the fluidization dead zone and even coking. In order to avoid coking, operators often use increased air volume, which further aggravates the wear of the hood.

\subsection{The reformation scheme and design optimization of air cap}

In order to solve the aforementioned issues with the conventional air caps, a new type of air cap has been designed according to the actual operation of the boiler (see Fig. 4). 

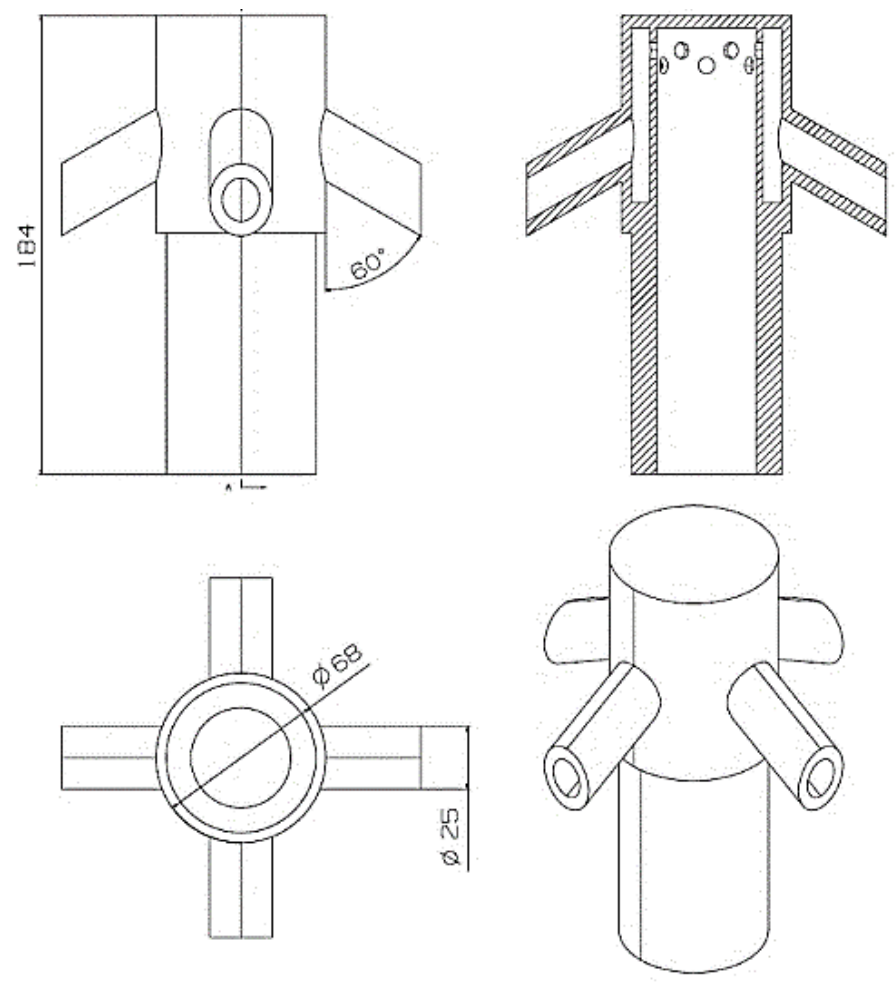

Fig. 4 Geometric details of novel air cap

The novel air cap proposed in this study is designed to extend the outlet holes of the nozzle downward and form an angle of $60^{\circ}$ with the vertical direction. It can greatly reduce the disturbance of the adjacent air holes of the air cap and the backflow of the bed material, hence, cover abrasion and broken are avoided. In the study of flow characteristics, it has been found that the air ejected from the outlet pipe of the novel air cap hits the bed material at the bottom of combustion chamber obliquely at high velocity, and then rebounds upwards. The air is fully mixed and dispersed with the bed material and fluidized, so that the velocity of the mixture of air and bed material is significantly reduced when it reaches the extended pipe of the air caps. It is well known that the velocity of the gas-solid mixture has a great influence on the abrasion of the air cap, therefore, the abrasion of the outlet pipe of the air cap is considerably reduced. In order to maintain the uniform air flow in the novel air cap, four outlet holes with large diameters, arranged in a circular array, have been designed. The inner core is specially designed with a series of small holes to ensures even distribution of air. Thus, the disturbance of bed 
material at the bottom is more sufficient and the fluidization is more uniform.

The length and angle of the outlet pipe of the novel air cap will affect the air flow and distribution in the furnace.

1. If the length of the outlet pipe of the novel air cap is too short, the inertia of the high velocity air ejected from the extended pipe is not adequate, resulting in the streamlines turning up too early. Therefore, the air cannot penetrate into the bed material layer at the bottom of the combustion chamber, resulting in poor fluidization.

2. If the length of the outlet pipe of the novel air cap is too long, air jets from any two adjacent outlet pipes will impact each other, resulting in uneven mixing with the bed material and part of the kinetic energy being wasted. Thus, the bed material cannot be fluidized more efficiently. Moreover, the bed material around the outlet pipes of the air caps cannot be disturbed effectively, resulting in the formation of local flow dead zones, which is very disadvantageous to boiler combustion.

3. If the angle of the novel air cap is too small, the penetration of high-velocity air jets from the novel air caps will be more than what is required, resulting in excessive abrasion of the air distribution plate and reduction in the operational life of the CFB boiler. This will also have significant impact on the flow structure within the boiler.

4. If the angle of the novel air cap is too large, air jets from any two adjacent outlet pipes will impact each other. Therefore, the momentum of the air ejected from the outlet pipes is not adequate to make the bottom bed material to be fully disturbed, resulting in uneven mixing, loss of thermal efficiency of the boiler and reduction in the operational life of the air caps.

In order to evaluate the performance of the retrofit, a series of cold tests using the novel air caps have been carried out. Through these tests, the characteristics of pressure drop and air flow penetration 
depth can be understood, and the corresponding characteristic curve, as well as empirical correlations, can be obtained.

\section{Mathematical modelling of the Novel Air Cap}

According to literature [5], the dynamic characteristics of air cap is mainly decided by two factors: pressure drop and air jet penetration length. Air caps with enhanced performance should have low pressure drop and optimal air jet penetration length. Therefore, it is very important to calculate the relationship between these two important kinetic parameters through mathematical derivation.

\subsection{Derivation of mathematical correlation for pressure drop across the air cap}

According to literature [19], pressure drop $(\Delta \mathrm{P})$ across the air cap can be expressed as follows:

$$
\begin{aligned}
& \Delta \mathrm{P}=\frac{\xi}{2} \rho \mathrm{v}^{2} \\
& \xi=\mathrm{a} \operatorname{Re}^{\mathrm{b}}
\end{aligned}
$$

Combining the above two equations:

$$
\Delta \mathrm{P}=\frac{\sum_{\mathrm{i}=1}^{5} \rho\left(\left|\mathrm{a}_{\mathrm{i}}\right| \mathrm{Re}_{\mathrm{i}}^{\mathrm{b}_{\mathrm{i}}}\right) \mathrm{v}_{\mathrm{i}}^{2}}{2}
$$

where subscript $i(1,2,3,4,5)$ corresponds to five resistance zones (i.e. cap outlet orifice, ring seam, core pipe orifice, cap turning point and core pipe) respectively. $a_{i}$ and $b_{i}$ are constants to be obtained through the regression of experimental data.

By definition:

$$
\operatorname{Re}=\frac{\rho v l}{\eta}
$$

where $\eta$ is the dynamics viscosity, $l$ is characteristic length and $\rho$ is the density of air. Therefore, we deduce:

$$
\Delta \mathrm{P}=\frac{\sum_{\mathrm{i}=1}^{5} \rho\left(\left|\mathrm{a}_{\mathrm{i}}\right|\left(\frac{\rho \mathrm{v}_{\mathrm{i}} \mathrm{l}_{\mathrm{i}}}{\eta}\right)^{\mathrm{b}_{\mathrm{i}}}\right) \mathrm{v}_{\mathrm{i}}^{2}}{2}
$$

where $\rho$ and $\eta$ are both constant. Simplifying Eq. (5), we get:

$$
\Delta \mathrm{P}=\sum_{\mathrm{i}=1}^{5}\left|\mathrm{n}_{\mathrm{i}}\right| \mathrm{l}_{\mathrm{i}}^{\mathrm{b}_{\mathrm{i}}} \mathrm{v}_{\mathrm{i}}^{\mathrm{b}_{\mathrm{i}}+2}
$$


where $\mathrm{n}_{\mathrm{i}}$ is a constant; and as shown in Fig. $5, l_{1}$ is the orifice diameter of cap outlet, $l_{2}$ is the average value of core pipe diameter and cap diameter, $l_{3}$ is the core pipe orifice diameter, $l_{4}$ is the height from top wall of core pipe to top wall of caps and $l_{5}$ is the core pipe diameter. From Fig. 5, it can be clearly seen that $l_{4}$ is equal to zero.

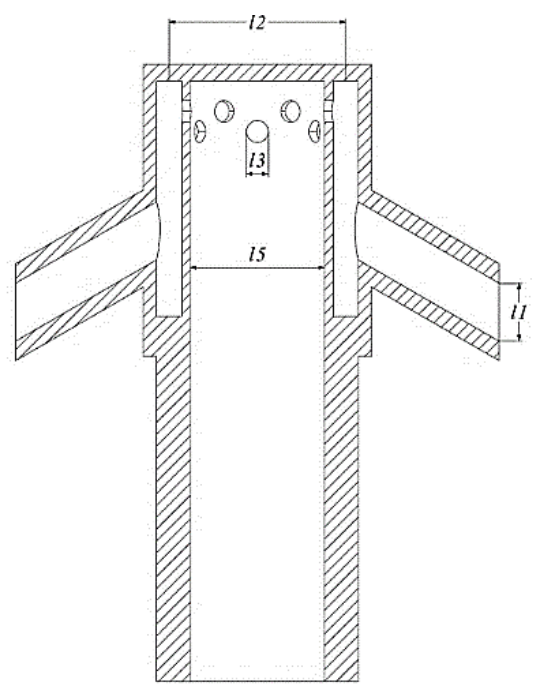

Fig. 5 Schematic diagram of the prototype nozzle

\subsection{Development of the mathematical correlation for pressure drop across the air cap}

The experimental results of pressure drop $(\Delta \mathrm{P})$ under six different conditions are shown in Table

1. The primary air volumetric flow rate in conditions $1-5$ is $1000,2000,3000,4000,5000$ and 6000 $\left(\mathrm{Nm}^{3} / \mathrm{h}\right)$ respectively.

In Table $1, v_{1}-v_{5}$ means the velocity flowing through $l_{1}-l_{5}$ cross sections respectively. Because $l_{4}$ is equal to 0 , so $\mathrm{v}_{4}$ equals 0 . Therefore, $\mathrm{v}_{4}$ does not exist in Table 1 . Velocity in $l 1$ and $l 5$ cross sections could be directly measured in velocity tester, velocity in $l 2$ and $l 3$ cross sections could be calculated according to the law of mass conservation. 
Table 1 The experimental results of pressure drop $(\Delta \mathrm{P})$

\begin{tabular}{ccccccc}
\hline & Condition 1 & Condition 2 & Condition 3 & Condition 4 & Condition 5 & Condition 6 \\
\hline $\mathrm{v} 1(\mathrm{~m} / \mathrm{s})$ & 5.9 & 11.79 & 17.68 & 23.58 & 29.47 & 35.37 \\
$\mathrm{v} 2(\mathrm{~m} / \mathrm{s})$ & 4.5 & 9.09 & 13.63 & 18.17 & 22.72 & 27.26 \\
$\mathrm{v} 3(\mathrm{~m} / \mathrm{s})$ & 10.55 & 21.10 & 31.65 & 42.20 & 52.75 & 63.30 \\
$\mathrm{v} 5(\mathrm{~m} / \mathrm{s})$ & 4.42 & 8.84 & 13.26 & 17.68 & 22.10 & 26.53 \\
$\Delta \mathrm{P}(\mathrm{Pa})$ & 544 & 1036 & 1738 & 2756 & 4179 & 6082 \\
\hline
\end{tabular}

The values of $a_{i}, b_{i}$ and $n_{i}$ can be obtained by regression of experimental data, as follows:

$$
\Delta \mathrm{P}=155.996 \mathrm{v}_{1}^{0.667}+0.0007 \mathrm{v}_{2}^{3.344}+0.0567 \mathrm{v}_{3}^{2.663}+0.0268 \mathrm{v}_{5}^{2.97}
$$

Details of the tests and the verification of Eq. (7) will be discussed in section 5.

\section{Derivation of mathematical correlation for air jet penetration length}

The schematic diagram of vertical downward jet of gas is shown in Fig. 6 [20].

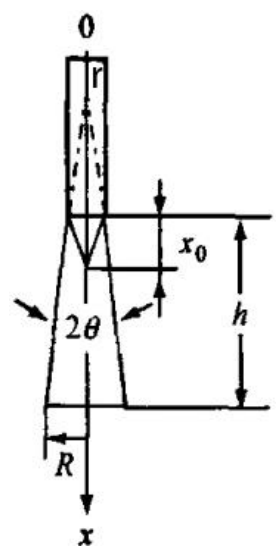

(a)

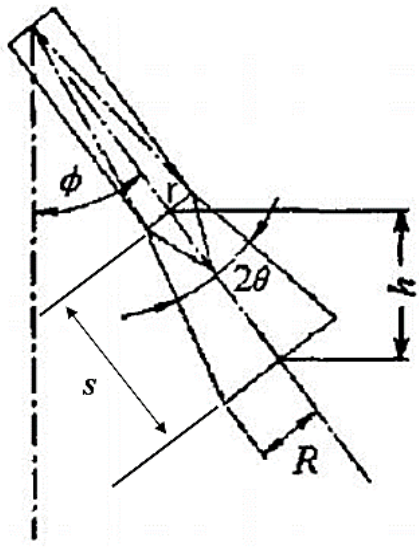

(b)

Fig. 6 Schematics of vertical jet depth [20]

In Fig. $6, \mathrm{r}$ is the jet nozzle radius, $\mathrm{s}$ is the total air jet penetration depth along the direction of the nozzle's outlet, $h$ is the vertical component of total air jet penetration depth $(h=s \cos \varphi)$, $R$ is the air 
jet penetration radius at penetration depth, the density of air jet is $\rho_{0}$, the average density of the surrounding medium is $\bar{\rho}$ and $\mathrm{V}$ is the volume of the surrounding medium. The air jet volume of the cap is:

$$
V=\pi r^{2} x_{0}+\frac{\pi}{3}\left(h-x_{0}\right)\left(R^{2}+r^{2}+R r\right)
$$

Diffusion of gas in medium is:

$$
\tan \theta=\mathrm{k}=\frac{\mathrm{R}-\mathrm{r}}{\mathrm{h}-\mathrm{x}_{0}}
$$

Therefore:

$$
\mathrm{R}=\mathrm{k}\left(\mathrm{h}-\mathrm{x}_{0}\right)+\mathrm{r}
$$

Inserting Eq. (10) into Eq. (8), we get:

$$
\begin{gathered}
V=\pi r^{2} x_{0}+\frac{\pi}{3}\left(h-x_{0}\right)\left(R(R+r)+r^{2}\right)=\pi r^{2} x_{0}+\frac{\pi}{3}\left(h-x_{0}\right)\left[k^{2} h^{2}+\left(3 k r-2 k^{2} x_{0}\right) h+\right. \\
\left.\left(k^{2} x_{0}^{2}-3 k r x_{0}+3 r^{2}\right)\right]
\end{gathered}
$$

As nozzle momentum is equal to the buoyancy of two-phase flow around the gas jet column, and the influence of the inclination angle, we get:

$$
\rho_{0} \pi r^{2}\left(u_{0} \cos \phi\right)^{2}=\bar{\rho} V g
$$

Thus, the following expression can be obtained:

$$
\mathrm{h}=\frac{1}{\bar{\rho} g \mathrm{k}} \sqrt[3]{\mathrm{r}^{2} \bar{\rho}^{2} \mathrm{~g}^{2}\left(3 \rho_{0} \mathrm{u}_{0}^{2} \mathrm{k}+\bar{\rho} \mathrm{gr}-3 \bar{\rho} g \mathrm{kx} x_{0}\right)}+\mathrm{x}_{0}-\frac{\mathrm{r}}{\mathrm{k}}
$$

Based on [21], $x_{0}=r, \theta=6.6^{\circ}$ and $\mathrm{k}=0.116$. Hence, the following equation is acquired:

$$
h=\frac{1}{\bar{\rho} g \mathrm{k}} \sqrt[3]{\mathrm{r}^{2} \bar{\rho}^{2} \mathrm{~g}^{2}\left(3 \rho_{0} \mathrm{u}_{0}^{2} \mathrm{k}+\bar{\rho} \mathrm{gr}-3 \bar{\rho} \mathrm{gkr}\right)}+\mathrm{r}-\frac{\mathrm{r}}{\mathrm{k}}
$$

The experimental verification of Eq. (14) will be discussed in section 5.

\section{Cold test of novel air caps}

For the purpose of conducting cold tests, it is a classical research method to simulate the actual bed material using water, and the corresponding model is called Water Model Experiment [22-26]. An 
advantage of this methodology is that the visualization is significantly better; the trajectory and distribution of air jets can be captured more effectively. This provides the preliminary research basis for follow-up hot tests in this study. Details of the cold test bed procedures, results and analysis are discussed below.

\subsection{Experimental set-up and procedure}

In order to verify the mathematical models obtained in the previous sections, and to analyze the flow uniformity of the novel air caps, cold tests have been carried out using a scaled model. Fig. 7 shows the test bed and its schematic. The test bed comprises of an air supply system and air caps. The air supply system is composed of a centrifugal fan and an air supply pipe. The air is driven by the centrifugal fan (1), through the pipeline, the valve (3), the glass rotameter (2), the air caps (6). It is then injected into the furnace (7) and then discharged to the atmosphere by exhaust pipe (4). The combustion chamber is made of Plexiglas and steel. Fifty air caps installed on the top wall of the windbox provide the primary air to the combustion chamber. The novel air caps have been connected to the air distribution plate by thread. This way, the height of the air cap can be adjusted according to the requirements, and the direction of the outlet pipe of the novel air cap can be adjusted to make them evenly arranged. The heights of all novel air caps are kept consistent, while the outlet pipes of adjacent air caps are opposite.

The pressure drop across the air caps and the fluidizing air rates have been monitored in the cold test performed. The pressure drop across the caps is measured by using U-tube pressure gauge (5). The outlet pressure is the same as the atmospheric pressure. Thus, the pressure drop of the hood is obtained. The fluidizing air rate can be directly recorded by the glass rotameter (2). 

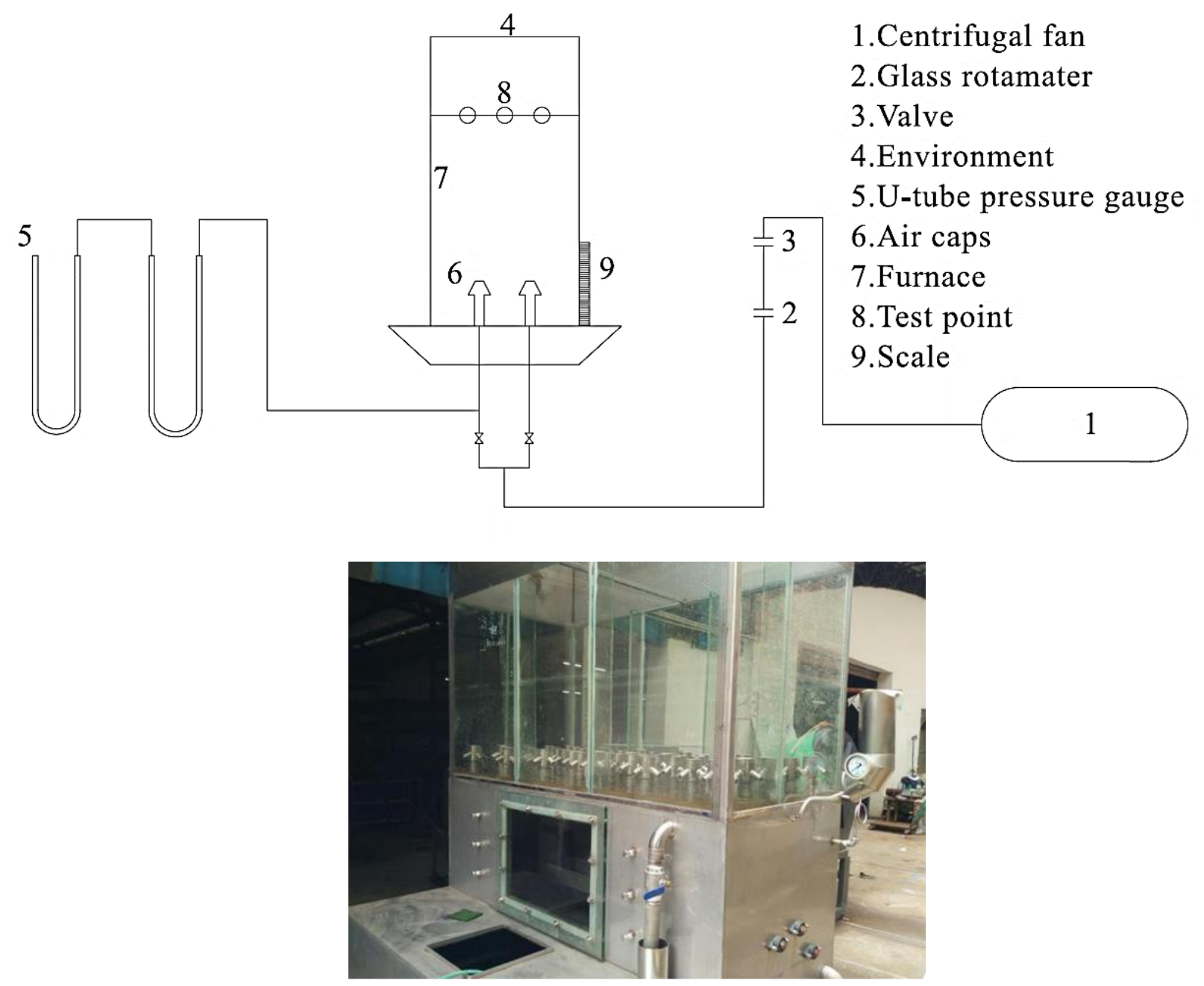

Fig. 7 Cold test bed

\subsection{Results and discussions}

The results obtained from cold test are discussed below.

\subsubsection{Pressure drop across the air novel air caps}

The experimental results for the pressure drop are shown in Fig.8. 


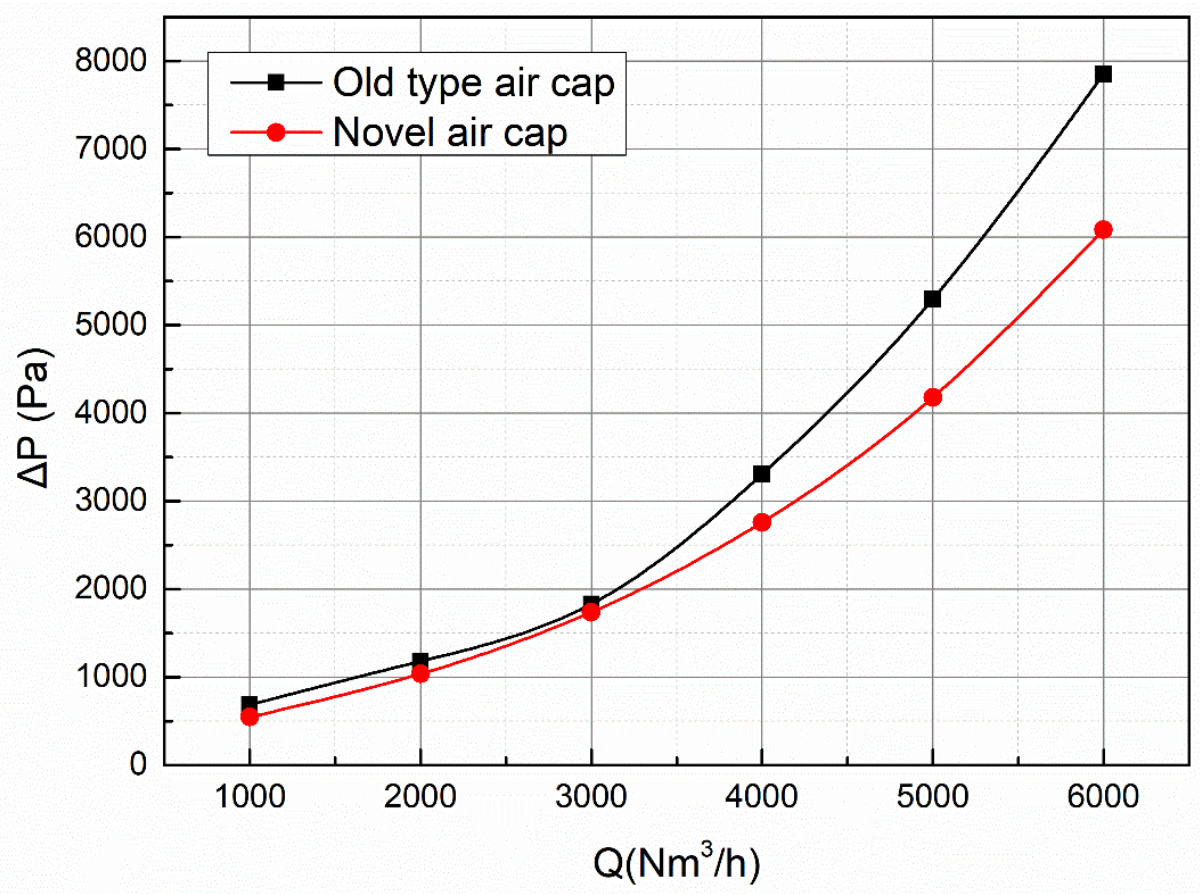

Fig. 8 Experimental results of the pressure drop

Comparing the pressure drop across the old type (conventional) and the novel air cap configurations, it can be seen that both these are a function of volumetric flow rate. Although at lower flow rates the pressure drop experienced by both the configurations is roughly the same, however, as the volumetric flow rate increases, the pressure drop across the novel air caps is recorded to be markedly less than the conventional air caps, and this difference increases as flow rate increases. The cold test results confirm the appropriateness of the novel air caps. The average pressure drop across the novel cap configuration, under six different test conditions, is $18.9 \%$ lower than that of the conventional cap configuration. Furthermore, as the outlet holes of the caps are at an angle of $60^{\circ}$ with the vertical direction, there is no bed material backflow.

\subsubsection{Verification of the mathematical pressure drop correlation for the novel air caps}

Based on mathematical correlation in Eq. (7), the calculated values of $\Delta \mathrm{P}$ are obtained. These calculated pressure drop values are compared against the cold test pressure drop values, and their relative errors computed, as shown in Table 2. 
Table 2 Relative error in pressure drop

\begin{tabular}{cccc}
\hline Condition & Calculated $\Delta \mathrm{P}(\mathrm{Pa})$ & Experimental $\Delta \mathrm{P}(\mathrm{Pa})$ & Relative Error $(-)$ \\
\hline Con. 1 & 542 & 544 & 0.003 \\
Con. 2 & 1018 & 1036 & 0.017 \\
Con. 3 & 1683 & 1738 & 0.031 \\
Con. 4 & 2638 & 2756 & 0.043 \\
Con. 5 & 3965 & 4179 & 0.051 \\
Con. 6 & 5734 & 6082 & 0.057 \\
\hline
\end{tabular}

From Table 2, it can be clearly seen that the calculated values are in good agreement with the experimental ones. The highest relative error does not exceed $1 \%$. This proves that the mathematical correlation in Eq. (5) is credible and can be used for accurate prediction of pressure drop across air caps.

\subsubsection{Error analysis of the mathematical correlation for pressure drop}

After conducting the cold tests, the reliability of the mathematical correlation for pressure drop needs to be evaluated using error analysis approach. The detailed description regarding the principles of error analysis can be found in [27].

$$
\Delta P=f\left(v_{1}, v_{2}, v_{3}, v_{5}\right)=f\left(X_{1}, X_{2}, X_{3}, X_{4}\right)
$$

Based on the principles of calculus, the following equation can be obtained:

$$
\Delta(\Delta \mathrm{P})=\frac{\partial \Delta \mathrm{P}}{\partial \mathrm{v}_{1}} \times \Delta \mathrm{v}_{1}+\frac{\partial \Delta \mathrm{P}}{\partial \mathrm{v}_{2}} \times \Delta \mathrm{v}_{2}+\frac{\partial \Delta \mathrm{P}}{\partial \mathrm{v}_{3}} \times \Delta \mathrm{v}_{3}+\frac{\partial \Delta \mathrm{P}}{\partial \mathrm{v}_{5}} \times \Delta \mathrm{v}_{5}=\sum_{\mathrm{i}=1}^{4} \mathrm{C}_{\mathrm{i}} \times \Delta \mathrm{X}_{\mathrm{i}}
$$

where $\Delta \eta_{\mathrm{gl}}$ is the test error in the pressure drop and $\Delta \mathrm{X}_{\mathrm{i}}$ is the measurement error of $\mathrm{X}_{\mathrm{i}} \cdot\left|\mathrm{C}_{\mathrm{i}}\right|=\left|\frac{\partial \Delta \mathrm{P}}{\partial \mathrm{X}_{\mathrm{i}}}\right|$ (the absolute value of partial derivative) reflects the influence of $\mathrm{X}_{\mathrm{i}}$ on $\Delta \mathrm{P}$, and is of great importance [28]. The calculated values of $\left|C_{i}\right|$ are shown in Fig. 9. 


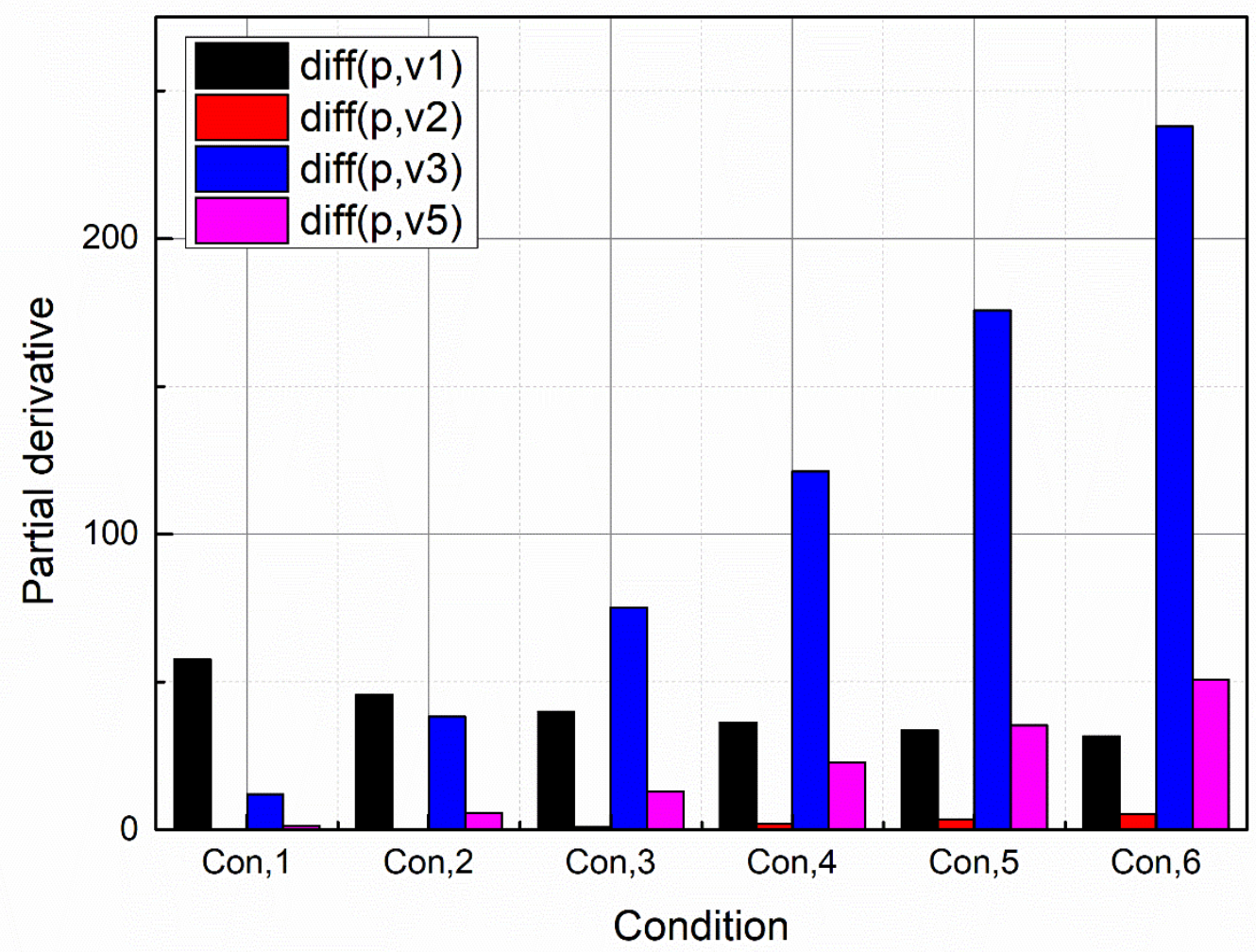

Fig. 9 Calculated values of $\left|\mathrm{C}_{\mathrm{i}}\right|$ for $\Delta \mathrm{P}$

From the results depicted in Fig. 9, it can be clearly seen that the maximum absolute value of the partial derivative is $\left|C_{3}\right|$ under all the working conditions considered. This means that $v_{3}$ is the most important factor affecting the pressure drop and special attention should be paid to this in engineering design of air caps.

\subsubsection{Verification of the mathematical air jet penetration length correlation}

Because the density of water is almost the same as that of the dense area of the fluidized bed, and that the water is transparent and easy to observe and photograph, it was considered to simulate the dense area at the bottom of circulating fluidized bed with a container filled with water. In this way, the behavior of the air jet from the caps, through the gas-solid fluidization zone in the dense phase, can be simulated by the behavior of the test bed air caps penetrating the static water in the water model.

In the cold tests, we have used the image method. A scale has been fixed beside the hood and a high-definition camera has been used to take photos of the jet under each experimental condition. An 
image processing software has been used to read the jet depth value. Since the mathematical correlation of the jet length has already been derived in Eq. (14), the comparative results of theoretical calculations and experimental measurements are presented in Fig. 10. It can be seen that the air jet penetration length increases linearly with the flow velocity in air caps, and that the theoretically calculated air jet penetration length values of the novel air cap configuration are in good agreement with the experimentally measured data.

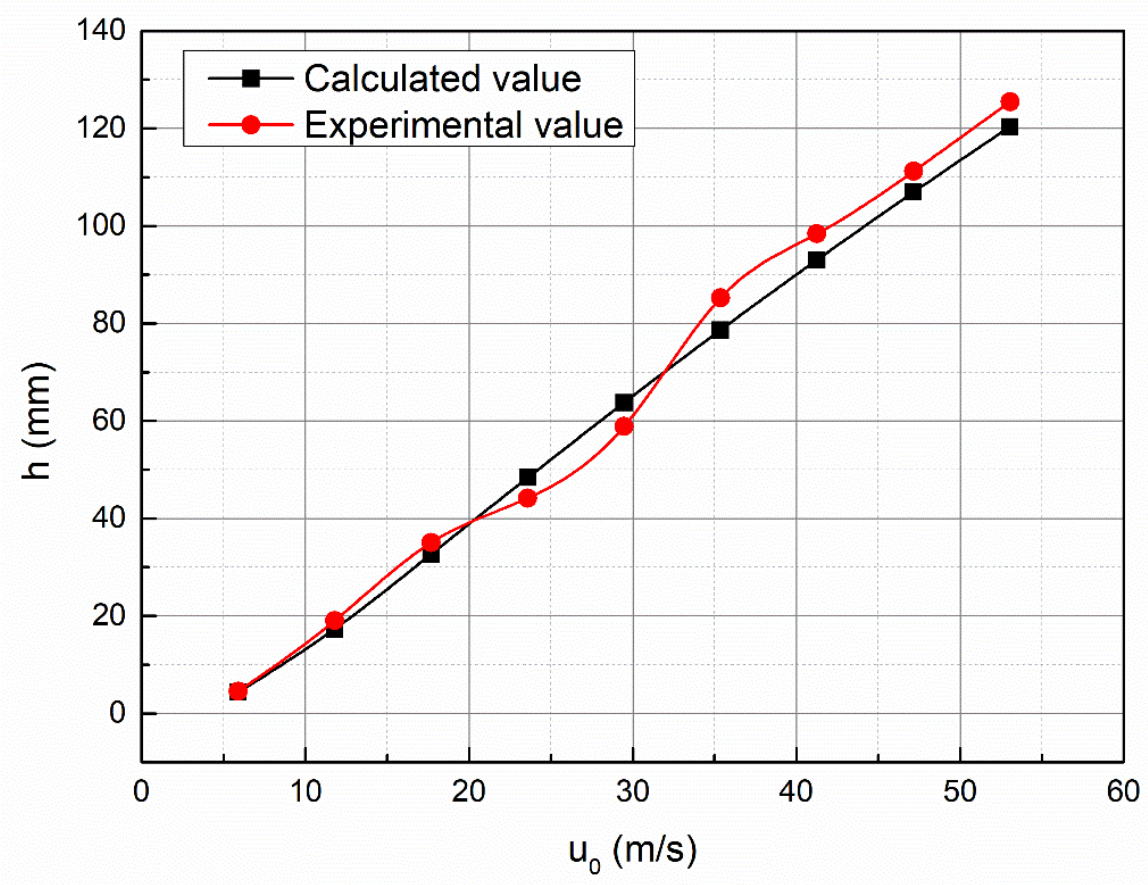

Fig. 10 Theoretical and experimental air jet penetration length values

Further analyzing the calculated and measured air jet penetration length values, Table 2 summarizes the relative error between these values. It can be seen that the theoretically calculated air jet penetration length values of the novel air cap configuration are in good agreement with the experimentally measured data, and that the maximum error is less than $10 \%$. It clearly shows that the mathematical correlation can be used for accurate predictions of air jet penetration length. 
Table 3 Relative errors in air jet penetration length

\begin{tabular}{cccc}
\hline $\mathrm{u}_{0}(\mathrm{~m} / \mathrm{s})$ & $\mathrm{h}$-Calculated $(\mathrm{mm})$ & $\mathrm{h}$-Experimental $(\mathrm{mm})$ & Relative Error $(-)$ \\
\hline 5.89 & 4.32 & 4.53 & 0.045 \\
11.79 & 17.28 & 19.01 & 0.090 \\
17.68 & 32.66 & 35.04 & 0.068 \\
23.58 & 48.39 & 44.18 & 0.095 \\
29.47 & 63.77 & 58.89 & 0.083 \\
35.37 & 78.68 & 85.23 & 0.077 \\
41.26 & 93.05 & 98.39 & 0.054 \\
47.16 & 106.95 & 111.22 & 0.038 \\
53.05 & 120.37 & 125.46 & 0.040 \\
\hline
\end{tabular}

\subsubsection{Error analysis of mathematical correlation for air jet penetration length}

The reliability of the mathematical correlation for air jet penetration length is evaluated in this section.

$$
h=f\left(r, \bar{\rho}, u_{0}\right)=f\left(X_{1}, X_{2}, X_{3}\right)
$$

Based on the principles of calculus, the following equation can be obtained:

$$
\Delta \mathrm{h}=\frac{\partial \mathrm{h}}{\partial \mathrm{r}} \times \Delta \mathrm{r}+\frac{\partial \mathrm{h}}{\partial \bar{\rho}} \times \Delta \bar{\rho}+\frac{\partial \mathrm{h}}{\partial \mathrm{u}_{0}} \times \Delta \mathrm{u}_{0}=\sum_{\mathrm{i}=1}^{3} \mathrm{C}_{\mathrm{i}} \times \Delta \mathrm{X}_{\mathrm{i}}
$$

where $\Delta \mathrm{h}$ is the test error in the penetration length of air jet and $\Delta \mathrm{X}_{\mathrm{i}}$ is the measurement error of $\mathrm{X}_{\mathrm{i}}$. $\left|C_{i}\right|=\left|\frac{\partial \Delta h}{\partial X_{i}}\right|$ is the value of $\left|C_{i}\right|$ which reflects the influence of $X_{i}$ on $\Delta h$, and is of great significance. The calculated values of $\left|C_{i}\right|$ are shown in Table 4 . 
Table 4 Calculated values of $\left|\mathrm{C}_{\mathrm{i}}\right|$ for $\Delta \mathrm{h}$

\begin{tabular}{ccc}
\hline$\partial \mathrm{h} / \partial \mathrm{r}$ & $\partial \mathrm{h} / \partial \bar{\rho}$ & $\partial \mathrm{h} / \partial \mathrm{u}_{0}$ \\
\hline 0.095 & $5.16 \mathrm{e}-05$ & 0.0018 \\
0.30 & $1.47 \mathrm{e}-05$ & 0.0025 \\
1.05 & $2.36 \mathrm{e}-05$ & 0.0027 \\
1.99 & $3.12 \mathrm{e}-05$ & 0.0026 \\
2.99 & $3.79 \mathrm{e}-05$ & 0.0026 \\
4.02 & $4.39 \mathrm{e}-05$ & 0.0025 \\
5.04 & $4.95 \mathrm{e}-05$ & 0.0024 \\
6.05 & $5.46 \mathrm{e}-05$ & 0.0023 \\
7.03 & $5.95 \mathrm{e}-05$ & 0.0022 \\
\hline
\end{tabular}

From the results summarized in Table 4, it can be clearly seen that the maximum absolute value of the partial derivative is $\left|C_{1}\right|$ under all the working conditions. This means that $r$ is the most important factor affecting the air jet penetration length and special attention should be paid to this in engineering design of air caps.

\subsubsection{Flow uniformity analysis in novel air caps}

In order to analyze the flow uniformity enhancements by using novel air caps in the CFB boiler, cold tests have been performed using both the conventional and the novel air caps (details of cold tests are in section 5.1). It has already been discussed in Fig. 7 that cross-sectional plane P1 has been considered for evaluating flow uniformity, while the details of the precise monitoring locations are presented in Fig. 11, namely u1 to u9. 
Plane P1

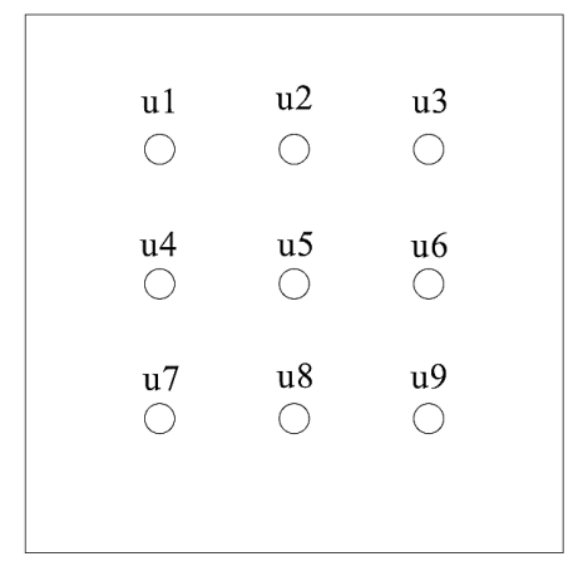

Fig. 11 Test points in the CFB boiler cold test bed

The cold test was conducted at $\mathrm{Q}=6000 \mathrm{~m}^{3} / \mathrm{h}$. The flow velocity values at aforementioned monitoring points have been recorded and summarized in Table 5, for both the air cap configurations. It is evident that the flow velocity in the novel air cap configuration is significantly higher than in the conventional air cap configuration, under the same operating conditions. This suggests that the resistance to the flow offered by the novel air caps is considerably lower than the conventional air caps, though this does not signify flow uniformity enhancement.

Table 5 Flow velocity at Plane P1

\begin{tabular}{ccc}
\hline Monitoring point & Flow velocity in & Flow velocity in novel air \\
& conventional air caps $(\mathrm{m} / \mathrm{s})$ & caps $(\mathrm{m} / \mathrm{s})$ \\
$\mathrm{u} 1$ & 2.65 & 5.15 \\
$\mathrm{u} 2$ & 1.58 & 5.08 \\
$\mathrm{u} 3$ & 1.47 & 4.93 \\
$\mathrm{u} 4$ & 2.32 & 4.55 \\
$\mathrm{u} 5$ & 2.5 & 4.97 \\
$\mathrm{u} 6$ & 1.33 & 4.78
\end{tabular}


u7

u8

u9

In order to evaluate the effectiveness of the novel air caps in terms of flow uniformity, inhomogeneity in the $\mathrm{z}$ component of flow velocity, at cross-sectional plane P1, has been used. The flow velocity inhomogeneity can be expressed as [29]:

$$
\varepsilon=\sqrt{\frac{1}{\mathrm{n}} \sum_{\mathrm{i}=1}^{\mathrm{n}}\left(\frac{\mathrm{u}_{\mathrm{i}}-\overline{\mathrm{u}}}{\overline{\mathrm{u}}}\right)^{2}} \times 100(\%)
$$

where $\varepsilon$ is the flow velocity inhomogeneity, $\mathrm{u}_{\mathrm{i}}$ is the local flow velocity in $\mathrm{z}$ direction at plane $\mathrm{P} 1, \overline{\mathrm{u}}$ is average flow velocity in $\mathrm{z}$ direction at $\mathrm{P} 1$ and $\mathrm{n}$ are the number of measurement points in plane P1. Flow velocity inhomogeneity on plane P1, in case of a conventional CFB boiler, has been computed to be $\varepsilon_{1}=63.21 \%$, while it is $\varepsilon_{2}=21.37 \%$ for the CFB boiler installed with the novel air caps. Thus, it can be inferred that flow velocity homogeneity significantly increases as novel air caps are installed in a CFB boiler. The effectiveness of air flow modifier is reflected by flow velocity inhomogeneity reduction on the plane $\mathrm{P} 1$, which can be expressed as:

$$
\Delta \varepsilon=\frac{\left(\varepsilon_{1}-\varepsilon_{2}\right)}{\varepsilon_{1}}
$$

where $\Delta \varepsilon$ is the percentage reduction in flow velocity inhomogeneity. $\Delta \varepsilon$ for the data in Table 5 has been computed to be $(63.21-21.37) / 63.21=70 \%$. This means that the novel air caps configuration is $66 \%$ more effective in uniformly distributing air flow within the primary air supply system of the CFB boiler compared to conventional air caps configuration.

The next step is to experimentally prove that the novel air cap configuration developed here actually improves air flow distribution within a CFB boiler. 


\section{Hot test results}

The final verification of the aforementioned results has been carried out by Guang Dong Special Equipment Test and Research Institute [2] in their hot test reports. The results of hot test are summarized in table 6.

Table 6 Results of hot test

\begin{tabular}{|c|c|c|c|c|c|}
\hline Test Items & Symbol & Unit & $\begin{array}{l}\text { Before } \\
\text { retrofit }\end{array}$ & $\begin{array}{l}\text { After } \\
\text { retrofit }\end{array}$ & $\begin{array}{c}\% \\
\text { change }\end{array}$ \\
\hline Carbon percentage of the received base & $\mathrm{Car}_{\mathrm{ar}}$ & $\%$ & 34.31 & 42.51 & 23.9 \\
\hline Hydrogen percentage of the received base & $\mathrm{H}_{\mathrm{ar}}$ & $\%$ & 2.33 & 2.86 & 22.7 \\
\hline Oxygen percentage of the received base & $\mathrm{O}_{\mathrm{ar}}$ & $\%$ & 14.99 & 10.89 & -27.3 \\
\hline Nitrogen percentage of the received base & $\mathrm{Nar}_{\mathrm{ar}}$ & $\%$ & 0.63 & 0.62 & -1.6 \\
\hline Sulphur percentage of the received base & $\mathrm{S}_{\mathrm{ar}}$ & $\%$ & 3.35 & 0.26 & -92.2 \\
\hline Water percentage of the received base & $\mathrm{Mar}_{\mathrm{ar}}$ & $\%$ & 18.31 & 17.89 & -2.3 \\
\hline Ash percentage of the received base & $\mathrm{A}_{\mathrm{ar}}$ & $\%$ & 29.24 & 24.97 & -14.6 \\
\hline Low calorific value & $\mathrm{Qdw}_{\mathrm{dw}}$ & $\mathrm{kJ} / \mathrm{kg}$ & 14170 & 15560 & 9.8 \\
\hline Unburned carbon content in slag & $\mathrm{C}_{\mathrm{dz}}$ & $\%$ & 2.59 & 3.69 & 42.5 \\
\hline $\begin{array}{c}\text { Percentage of slag content accounting for the } \\
\text { total ash content }\end{array}$ & $\alpha_{\mathrm{d} z}$ & $\%$ & 30 & 30 & 0.0 \\
\hline Unburned carbon content in fly ash & $\mathrm{C}_{\mathrm{fh}}$ & $\%$ & 0.47 & 2.01 & 327.6 \\
\hline $\begin{array}{c}\text { Percentage of fly ash content accounting for } \\
\text { the total ash content }\end{array}$ & $\alpha_{\mathrm{fh}}$ & $\%$ & 70 & 70 & 0.0 \\
\hline Exhaust flue gas temperature & $\theta_{\text {py }}$ & ${ }^{\circ} \mathrm{C}$ & 171.2 & 140 & -18.2 \\
\hline
\end{tabular}


Oxygen content in exhaust flue gas

CO content in exhaust flue gas
$\mathrm{VO} 2$

$\mathrm{V}_{\mathrm{CO}}$

q3

$$
\%
$$

0.06

0.06

0.0

flammable gas

Heat loss from incomplete combustion of

$\begin{array}{lllll}\mathrm{q}_{4} & \% & 0.633 & 0.633 & 0.0\end{array}$

solid

Heat loss from boiler radiation

q5

$$
\%
$$

0.4

0.4

0.0

\section{Heat loss from ash slag}

Thermal efficiency of boiler $\mathrm{q} 6$

$\eta$
$\%$

0.2226
$\%$

\section{4}

0.2226

\section{$91.8 \quad 6.2$}

It should be noted that the difference in calorific values of coal used before and after retrofit is less than $10 \%$. Due to the extensive fuel adaptability of CFB boiler, coal with different calorific value can be combusted in CFB boiler effectively, and the fuel with calorific values difference less than $20 \%$ has little effect on the thermal efficiency of CFB boiler according to our experience. It can be seen towards the end of the table that heat losses in the $220 \mathrm{t} / \mathrm{hr}$ CFB boiler, installed with novel air caps, have significantly decreased. Hence, the thermal efficiency of the boiler has been shown to increase from $86.4 \%$ to $91.8 \%$, which is equivalent to savings of 6,000 tons of coal per year. The economic benefits of this energy-saving technology are very significant, and hence, it confirms the effectiveness of the optimally designed air flow modifier (air caps). Further investigations are required in order to gauge the effects of the developed nozzle design on abrasion, cover damage, holes plugging and inner core tube rupture.

\section{Error analysis of the thermal efficiency of CFB boiler}

After conducting the hot test, the reliability of CFB boiler's thermal efficiency needs to be 
evaluated using error analysis approach. The boiler's thermal efficiency can be expressed as:

$$
\eta_{\mathrm{gl}}=\mathrm{q}_{1}=100-\sum_{\mathrm{i}=2}^{6} \mathrm{q}_{\mathrm{i}}(\%)
$$

where $\mathrm{q}_{\mathrm{i}}(\mathrm{i}=1,2,3,4,5$ and 6$)$ represents net heat $\left(\mathrm{q}_{1}\right)$, heat loss due to exhaust gas $\left(\mathrm{q}_{2}\right)$, heat loss due to unburned gas $\left(\mathrm{q}_{3}\right)$, heat loss due to unburned carbon $\left(\mathrm{q}_{4}\right)$, heat loss due to radiation $\left(\mathrm{q}_{5}\right)$ and heat loss due to sensible heat in slag $\left(\mathrm{q}_{6}\right)$ respectively. According to [30], the following empirical equations can be used to calculate the values of $\mathrm{q}_{2}, \mathrm{q}_{3}, \mathrm{q}_{4}, \mathrm{q}_{5}$ and $\mathrm{q}_{6}$ :

$$
\mathrm{q}_{2}=\left(\mathrm{m}+\mathrm{n} \alpha_{\mathrm{py}}\right)\left(1-\frac{\mathrm{q}_{4}}{100}\right) \frac{\theta_{\mathrm{py}}-\mathrm{t}_{\mathrm{amb}}}{100}(\%)
$$

where $\mathrm{m}=0.5, \mathrm{n}=3.45, \alpha_{\mathrm{py}}$ is excess air coefficient, $\theta_{\mathrm{py}}$ is exhaust gas temperature and $\mathrm{t}_{\mathrm{amb}}$ is ambient temperature.

$$
\mathrm{q}_{3}=\lambda \alpha_{\mathrm{py}} \mathrm{V}_{\mathrm{CO}}(\%)
$$

where $\lambda=3.2$ and $\mathrm{V}_{\mathrm{CO}}$ is the volume percentage of $\mathrm{CO}$ in exhaust flue gas.

$$
\mathrm{q}_{4}=\frac{B \mathrm{~A}_{\mathrm{ar}}}{\mathrm{Q}_{\mathrm{r}}}\left(\frac{\mathrm{a}_{\mathrm{hz}} \mathrm{C}_{\mathrm{hz}}}{100-\mathrm{C}_{\mathrm{hz}}}+\frac{\mathrm{a}_{\mathrm{fh}} \mathrm{C}_{\mathrm{fh}}}{100-\mathrm{C}_{\mathrm{fh}}}\right)(\%)
$$

where $\mathrm{B}$ is the calorific value of combustible material $(33700 \mathrm{~kJ} / \mathrm{kg}), \mathrm{A}_{\mathrm{ar}}$ is the ash percentage of the received base in $\%, \mathrm{Q}_{\mathrm{r}}$ is the low calorific value of the received basis in $\mathrm{kJ} / \mathrm{kg}, \mathrm{C}_{\mathrm{hz}}$ and $\mathrm{C}_{\mathrm{fh}}$ represent the weight percentage of combustible material in coal slag and fly ash in \% respectively, and ahz and afh represent the percentage of coal slag content and fly ash content in total amount of fuel ash in $\%$ respectively. In the current study, according to [31], $\mathrm{ahz}_{\mathrm{z}}=0.2$ and $\mathrm{afh}=0.8$.

$$
\mathrm{q}_{5}=-\frac{\mathrm{hX}}{100 \mathrm{x}_{0}}+\mathrm{d}(\%)
$$

where $\mathrm{h}=0.33, \mathrm{~d}=0.495, \mathrm{X}_{\mathrm{o}}$ and $\mathrm{X}$ are the rated and current loads of the boiler respectively.

$$
\mathrm{q}_{6}=\mathrm{a}_{\mathrm{hz}} \frac{100}{100-\mathrm{C}_{\mathrm{hz}}}(\mathrm{c} \vartheta)_{\mathrm{hz}} \frac{\mathrm{A}_{\mathrm{ar}}}{\mathrm{Q}_{\mathrm{r}}}
$$

where (c9)hz is the enthalpy of coal slag. Combining Eqs. (20-24):

$$
\eta_{\mathrm{gl}}=100-\left[\left(\mathrm{m}+\mathrm{n} \alpha_{\mathrm{py}}\right)\left(1-\frac{\mathrm{q}_{4}}{100}\right) \frac{\theta_{\mathrm{py}}-\mathrm{t}_{\mathrm{amb}}}{100}+\lambda \alpha_{\mathrm{py}} \mathrm{V}_{\mathrm{CO}}+\frac{\mathrm{B} \mathrm{A}_{\mathrm{ar}}}{\mathrm{Q}_{\mathrm{r}}}\left(\frac{\mathrm{a}_{\mathrm{hz}} \mathrm{C}_{\mathrm{hz}}}{100-\mathrm{C}_{\mathrm{hz}}}+\frac{\mathrm{a}_{\mathrm{fh}} \mathrm{C}_{\mathrm{fh}}}{100-\mathrm{C}_{\mathrm{fh}}}\right)+\right.
$$




$$
\left.\left(-\frac{h X}{100 X_{0}}+d\right)+a_{h z} \frac{100}{100-C_{h z}}(c \vartheta)_{h z} \frac{A_{a r}}{Q_{r}}\right]
$$

where [32]:

$$
\begin{gathered}
(\mathrm{c} \vartheta)_{\mathrm{hz}}=0.0002887 \theta_{\mathrm{py}}^{2}+0.6851 \theta_{\mathrm{py}}+26.76 \\
\alpha_{\mathrm{py}} \approx \frac{0.21}{0.21-\mathrm{V}_{\mathrm{O} 2}}
\end{gathered}
$$

Thus:

$$
\eta_{\mathrm{gl}}=\mathrm{f}\left(\theta_{\mathrm{py}}, \mathrm{V}_{\mathrm{O}_{2}}, \mathrm{~V}_{\mathrm{CO}}, \mathrm{C}_{\mathrm{fh}}, \mathrm{C}_{\mathrm{hz}}, \mathrm{A}_{\mathrm{ar}}, \mathrm{Q}_{\mathrm{r}}\right)=\mathrm{f}\left(\mathrm{X}_{1}, \mathrm{X}_{2}, \mathrm{X}_{3}, \mathrm{X}_{4}, \mathrm{X}_{5}, \mathrm{X}_{6}, \mathrm{X}_{7}\right)
$$

Based on the principles of calculus, the following equation can be acquired:

$$
\Delta \eta_{\mathrm{gl}}=\frac{\partial \eta_{\mathrm{gl}}}{\partial \theta_{\mathrm{py}}} \times \Delta \theta_{\mathrm{py}}+\frac{\partial \eta_{\mathrm{gl}}}{\partial \mathrm{V}_{\mathrm{O}_{2}}} \times \Delta \mathrm{V}_{\mathrm{O}_{2}}+\cdots+\frac{\partial \eta_{\mathrm{gl}}}{\partial \mathrm{Q}_{\mathrm{r}}} \times \Delta \mathrm{Q}_{\mathrm{r}}=\sum_{\mathrm{i}=1}^{7} \mathrm{C}_{\mathrm{i}} \times \Delta \mathrm{X}_{\mathrm{i}}
$$

where $\Delta \eta_{\mathrm{gl}}$ is the test error in the thermal efficiency of the boiler, $\Delta \mathrm{X}_{\mathrm{i}}$ is the measurement error in $\mathrm{X}_{\mathrm{i}}$, $\mathrm{C}_{\mathrm{i}}=\frac{\partial \eta_{\mathrm{gl}}}{\partial \mathrm{X}_{\mathrm{i}}}=\frac{\Delta \eta_{\mathrm{gl}}}{\Delta \mathrm{X}_{\mathrm{ii}}}$ where $\Delta \mathrm{X}_{\mathrm{ii}}$ is fractional change in $\mathrm{X}_{\mathrm{i}}(0.1 \%)$ and $\Delta \eta_{\mathrm{gl}}$ is the variation in $\eta_{\mathrm{gl}}$ caused by $\Delta \mathrm{X}_{\mathrm{ii}}$. The results of the error analysis for the $220 \mathrm{t} / \mathrm{hr}$ CFB boiler are summarized in Table 7 . It can be

\begin{tabular}{|c|c|c|c|c|c|c|c|}
\hline Items & Symbol & Unit & Value & Accuracy & $\Delta \mathrm{Xi}$ & $\mathrm{Ci}$ & $\mathrm{Ci} * \Delta \mathrm{Xi}$ \\
\hline $\begin{array}{c}\text { Exhaust flue gas } \\
\text { temperature }\end{array}$ & $\theta$ py & ${ }^{\circ} \mathrm{C}$ & 140 & 0.1 & 0.1 & 0.00427 & 0.000427 \\
\hline Oxygen content & & & & & & & \\
\hline $\begin{array}{c}\text { in exhaust flue } \\
\text { gas }\end{array}$ & $\mathrm{VO} 2$ & $\%$ & 8 & 0.01 & 0.0008 & 0.014 & $1.08 \mathrm{e}-05$ \\
\hline CO content in & $\mathrm{VCO}$ & $\%$ & 0.048 & $1 \mathrm{ppm}$ & 0.000001 & 5.377 & $5.38 \mathrm{e}-06$ \\
\hline
\end{tabular}
clearly seen that the maximum test error in the thermal efficiency of the $220 \mathrm{t} / \mathrm{h}$ CFB boiler is $0.034 \%$. Hence, the results presented in table 6 regarding the increase in the thermal efficiency of the 220t/hr CFB boiler (by 6.2\%), after the installation of novel air caps is thus confirmed.

Table 7 Results of error analysis 
exhaust flue gas

Unburned carbon

$\begin{array}{lllllll}\text { Cfh } & \% & 2.01 & 1 & 0.0201 & 0.4485 & 0.009\end{array}$

content in fly ash

Unburned carbon

$\begin{array}{lllllll}\text { Chz } & \% & 3.69 & 1 & 0.0369 & 0.1165 & 0.004\end{array}$

content in slag

Ash percentage of
Aar
$\%$
24.97
0.5
0.125
0.0536
0.007

the received base

Low calorific

value

$\begin{array}{lllllll}\text { Qr } & \mathrm{kJ} / \mathrm{kg} & 15560 & 1 & 155.6 & 0.000086 & 0.013\end{array}$

Test error in the

$\Delta \eta \mathrm{gl} \quad \%$

0.034

thermal efficiency

\subsection{Conclusions}

The primary aim of the present study is to carry out theoretical and experimental investigations on the development and use of novel air caps in a 220t/hr CFB boiler, in order to increase its thermal efficiency. Mathematical correlations have been developed for air pressure drop and air jet penetration length from air caps. Cold tests on a scaled CFB boiler model, installed with novel air caps, have been carried out to verify the accuracy of the developed correlations, under varying operating conditions. analyze the of novel air cap. The average pressure drop across the novel air caps has been recorded to be $18.9 \%$ lower than conventional air caps. Moreover, through the cold test, it has been noticed that uniformity in air flow has significantly improved; inhomogeneity is reduced by $66 \%$. As the novel air caps have outlets at an angle of $60^{\circ}$ vertically, it has been observed that air flow from the caps do not impact the wall surfaces directly, and that there is no bed material backflow. Thus, the abrasion of the 
air cap and ash deposition is significantly reduced. The same methodology has been implemented to a full scale $220 \mathrm{t} / \mathrm{hr}$ CFB boiler as well. According to the results of the hot test performed on a $220 \mathrm{t} / \mathrm{hr}$ CFB boiler, the thermal efficiency of the boiler increases from $86.4 \%$ to $91.8 \%$ when novel air caps are used. This increase in the thermal efficiency of the CFB boiler corresponds to an equivalent saving of 6,000 tons of coal per year. The economic benefits of this energy-saving technology are very thus very significant.

\section{Acknowledgements}

This work is supported by the Scientific and Technological Plan of Guangdong Province (No. 2017A040405049).

\section{References}

[1] G. Yue, R. Cai, J. Lu and H. Zhang (2017) From a CFB reactor to a CFB boiler - The review of R\&D progress of CFB coal combustion technology in China, Powder Technology (7) 18-28.

[2] L. Li (2017) Hot test report of a 220t/hr CFB boiler before retrofit, Report submitted to Guang Dong Special Equipment Test and Research Institute.

[3] P. Mirek (2011) Designing of primary air nozzles for large-scale CFB boilers in a combined numerical-experimental approach, Chemical Engineering and Processing (50) 694-701.

[4] Y. Zhang, M. Zhang, S. Zhu, Y. Huang, B. Deng, X. Gao, X. Jiang, J. Lyu and H. Yang (2019) Mechanism analysis of gas solid flow non-uniformity problem of 330 MW CFB boiler, Chemical Engineering Research and Design (145) 258-267.

[5] P. Mirek and M. Klajny (2018) Air nozzle design criteria for protection against the backflow of solids in CFB boilers, Applied Thermal Engineering (141) 503-515.

[6] C. Niu (2018) Research on resistance characteristics and structure optimization of bell type cap in 
CFB boiler, MSc thesis, North China Electric Power University, China.

[7] F. Jinlong (2015) Study on resistance characteristics of air caps and maldistribution of distributor in large fluidized bed, MEng thesis submitted to the University of Chinese Academy of Sciences, China. [8] X.J. Yi, Q.G Lv, Z.P. Zhu and J. He (2011) Experimental study on the leak proof characteristics of the built-in counter current column type cap, Journal of Engineering for Thermal Energy and Power 26(002) 212-215.

[9] Z.N. Xiao, H. Xu, W.F. Wu and C.S. Hao (2013) Experiment method of large scale CFB boiler nozzle resistance characteristics, Power System Engineering (6) 30-32.

[10] H.R. Yang, Z.M. Huang, G.X. Yue and J.F. Lu (2007) Characteristics of a float nozzle designed for circulating fluidized bed boilers, Chemical Engineering Technology (30) 1398-1400.

[11] W.H. Li and X.H. Guo (2009) Numerical calculation and structural optimization of resistance characteristics of T-type air cap in CFB boiler, Journal of Thermal Science and Technology (4) 48-52. [12] B.X. Feng, Z.Q. Miu, J.Q. Pan, Z.Y. Yu, M. Zhang and D.B. Zheng (2008) Test obtained pressure drop characteristics of three typical distributor plate nozzles in circulating fluidized bed boilers, Journal of Power Engineering (1) 24-27.

[13] C.L. Briens and A. Bergougnou (1990) Prediction of the flux of particles re-entrained through the grid, Powder Technology (62) 59-66.

[14] Z.M. Huang, H.R. Yang, Q. Liu, Y. Wang, J.F. Lu and G.X. Yue (2010) Characteristics of a modified bell hood nozzle designed for CFB boilers, Proceedings of the $20^{\text {th }}$ International Conference on Fluidized Bed Combustion, 492-495.

[15] H. Zhong (2014) Optimization of large-diameter bell-type air cap in CFB boiler, Power Construction (35) 84-87. 
[16] P. Xin, M. Luowei and J. Jianzhong (2010) Operation and improvement of 300 MW circulating fluidized bed boiler developed by Dongfang Boiler Group, Electric Power Construction (5) 108-110. [17] Q. Juan, Z. Shanxiang (2003) Application of bell-type hood on circulating fluidized bed boiler, Energy Conservation and Environmental Protection (8) 38-39.

[18] M. Jiang and P. Xiao (2009) Large-scale circulating fluidized bed boiler technology, Electric Power Press, Beijing, China

[19] A.M. David, A. Jack and A. Stuart (1999) An experimental study of viscous flows in contractions, Journal of Loss Prevention in the Process Industries (12) 249-258.

[20] Z. Miu, B.X. Feng, J.D. Liu, J.Q. Pan, F. Guan and C.H. Ren (2007) Research on how deep jets coming from downwards directed air nozzles can penetrate into bed layers, Journal of Power Engineering (6) 899-902.

[21] Z.N. Xiao, Z.W. Zhao, W.F. Wu, H.G. Li and R.Q. Jiao (2010) Experiment on penetration depth of nozzle jets of circulating fluidized bed boiler, Journal of Inner Mongolia University of Science and Technology (29) 263-266.

[22] B.T. Maia, R.K. Imagawa, A.C. Petrucelli and R.P. Tavares (2014) Effect of blow parameters in the jet penetration by physical model of BOF converter, Materials Research and Technology (3) 244256.

[23] B. Zhu, K. Chattopadhyay, X. Hu, B. Zhang, Q. Liu and Z. Chen (2018) Optimization of sampling location in the ladle during RH vacuum refining process, Vacuum (152) 30-39.

[24] X. Ai, Y. Bao, W. Jiang, J. Liu, P. Li and T. Li (2010) Periodic flow characteristics during RH vacuum circulation refining, International Journal of Minerals, Metallurgy, and Materials, (17) 17-21. [25] L. Lin, Y. Bao, F. Yue, L. Zhang and H. Ou (2012) Physical model of fluid flow characteristics in 
RH-TOP vacuum refining process, International Journal of Minerals, Metallurgy and Materials (19) 483-489.

[26] S. Zheng and M. Zhu (2016) Modelling effect of circulation flow rate on inclusion removal in RH degasser, Journal of Iron and Steel Research International (23) 1243-1248.

[27] P.R. Bevington and D.K. Robinson (1992) Data Reduction and Error Analysis for the Physical Sciences, $3^{\text {rd }}$ ed., McGraw-Hill, New York, USA.

[28] F. Rahimpour, R. Zarghami and N. Mostoufi (2017) Effect of distributor on fluidized bed hydrodynamics, Chemical Engineering (95) 2221-2234.

[29] J. Zhu, Z. Ouyang and Q. Lu (2013) Numerical simulation on pulverized coal combustion and $\mathrm{NO}_{\mathrm{x}}$ emissions in high temperature air from circulating fluidized bed, Journal of Thermal Science (22) 261-268.

[30] J. Wu, Y. Zhang, G. Xu, Y. Lin and X. Lv (2014) Research on the optimization of boiler efficiency based on artificial bee colony algorithm, Computer and Information Science (7) 30-38.

[31] X.J. Zhuo, J.Y. Liu, J.W. Wang and L.C. Ju (2012) Analysis and application of uncertainty in antibalancing thermal efficiency of boilers, Thermal Power Generation (2) 32-36. (in Chinese)

[32] R. Cai and Y. Zhang (2016) Force characteristic of a large dense object in a fluidized bed equipped with an inclined air distributor, Advanced Powder Technology (27) 599-609. 